\title{
Construct and Convergent Validity of the OIS-García (Optimist Interactive Style) Scales in a Mexican Population
}

\author{
Cirilo H. García \\ Universidad Autónoma de Nuevo \\ León, Monterrey, México
}

\author{
Héctor L. Díaz \\ The University of Texas-Pan \\ American, Edinburg, USA
}

\author{
Arnoldo Téllez, Fuensanta \\ López, Juan Martínez, Lorenzo \\ Sánchez, Enrique García \\ Universidad Autónoma de Nuevo \\ León, Monterrey, México
}

\begin{abstract}
This is a report of the validation process of two scales that measure the OIS-García (optimist interactive style). An attempt was made to establish construct and convergent validity for these two scales. Towards this end, we relied on the Spanish version of the LOT-R (life orientation test-revised). Participants were 350 relatives of a cancer patient with a mean age of 39.87 years $(S D=14.88)$ and an age range going from 15 to 79 years. Each of the new versions of the OIS1-García and OIS2-García comprised 10 items. The Chronbach alpha internal consistency coefficients were 0.701 for the OIS1 and 0.633 for the OIS2. The Spearman correlation coefficient among these two tests was 0.438, the correlation among LOT-R and OIS1-García was 0.382, and the correlation among LOT-R and OIS2-García was 0.468 . As a result, we were able to partially validate both versions of the OIS-García test. These findings serve as encouragement to develop more culturally sensitive and appropriate measurement instruments for specific cultures or populations.
\end{abstract}

Keywords: validation, construct and convergent validity, optimism, Mexicans

\section{Introduction}

According to interbehavioral psychology, the OIS-García (optimist interactive style) refers to our disposition and ability to interact in and with our social and inanimate world in a favorable and positive way with the expectation that something good will result from that interaction. All of this is expected to happen while thinking positively about our behaviors and knowing that we want to receive good things and offer others the best in us (Kantor, 1959; Kantor \& Smith, 1975; Ribes \& Sánchez, 1992). This is basically an interactive process: People with this interactive style believe that the world is pleasant and good and so are they. Consequently, there is a good match and there are no conflicts or contradictions they cannot overcome. They consider and perceive others and themselves as good people, they trust others and themselves, and may even believe in the innate goodness of people. Furthermore, they believe that life has been good to them, that it is

Cirilo H. García, Ph.D., professor, Facultad de Psicologia, Universidad Autónoma de Nuevo León.

Héctor L. Díaz, professor and former Chair of the School of Social Work, The University of Texas-Pan American.

Arnoldo Téllez, professor, Facultad de Psicologia, Universidad Autónoma de Nuevo León.

Fuensanta López, professor, Facultad de Psicologia, Universidad Autónoma de Nuevo León.

Juan Martínez, professor, Facultad de Psicologia, Universidad Autónoma de Nuevo León.

Lorenzo Sánchez, professor, Facultad de Psicologia, Universidad Autónoma de Nuevo León.

Enrique García, professor, Facultad de Psicologia, Universidad Autónoma de Nuevo León. 
good and beautiful, that there are solutions to all problems, and that the world and all of us are now better than in the past. Finally, hope is an important characteristic of such positive disposition because they believe in and look forward to a better future, not only for individuals but for the whole human race. The theory proposes that there is something better in the future for everyone.

According to interbehavioral psychology, people's adjustments or adaptations to their environment (which is in essence psychological) are facilitated by their "interactive styles". Such styles have emerged as a result of an evolutionary process of the total interactions between the environment and them, which in turn ontogenetically represent each person’s individuation (Ribes \& Sánchez, 1990; Ribes, 2005). Variations in interactive styles within one person deserve to be the subject of our study given that interactive styles represent specific and particular learned ways of interaction and a functional aspect of our personalities (Ribes, 2005; 2009). At the same time, it is possible and desirable to identify and compare personality interactive styles across individuals by creating situations that include broad and diverse stimuli and provide enough possible proxy responses that represent the selected interactive behaviors in a valid and reliable way. This would ultimately be cultural behavior (Kantor, 1982). In other words, cultural behaviors would be those interactive behaviors shared by the subjects because they belong to a particular group of people. We wish to discover how the subjects in our study would eventually respond to situations addressed by the items in our Likert-type scale. Their responses are estimates of the probability that they will rely on a particular interactive style given the situations presented to them by sampling contexts referenced via sentences, not beliefs belonging to an inexistent mental realm (Piña, Ybarra, Alcalá, \& Samaniego, 2010). Subjects must respond to a complex stimulus situation through a Likert-type scale that contains items as well as four possible responses for each item.

In this study we rely on the concept from interbehavioral psychology called "psychological act" or "behavioral segment". For example, the act of reading the sentence or item and selecting an answer represents a reaction pattern. The second psychological act is tied to the previous one and is constituted by the selected response integrated to the original phrase (e.g., it seems like life is in fact beautiful) (as a stimulus object). This is in turn connected to another system of responses that would ultimately be positively linked to the real world.

The sum of scores in the scale provides us with an estimate of the probability that the individual possesses a particular interactive style to an extent different from other people.

The random ordering of the scale items and the inclusion in the scale of a variable number of items ranging from 6 to 15, enhance the probability of having total scores that validly measure the proper interactive style. Consistent with this, the case reported in this study is the "OIS-García".

These ideas about the OIS-García that stem from the interbehavioral metatheory are consistent with the definition of optimism provided by the Dictionary of the Spanish Language (Academy Royal of the Spanish Language, 2001). Said dictionary defines optimism as the "tendency to see and judge things in a more favorable way". We would interpret the word "things" as including other people as well as those who "see and judge”. In this sense, even English-speaking psychologists share this definition given that they also view optimism as "a tendency to expect the best possible result and to highlight the positive aspects of all situations" (Matsumoto, 2009). Similarly, here we would interpret the word "situations" in the definition as making reference to others as well as the optimist person himself.

We pose the question: Is optimism an emotion? What are the emotions from a psychological point of view? 
We could say that emotions are specials ways of interacting with our physical and social environment, and means for adaptation. Let us now use the psychological act or behavioral segment as a descriptive unit of an emotion (Kantor, 1969).

For example, if something does not work out as expected (the stimulus object as primary psychological datum), an episode of anger could take place (the response, also as a primary psychological datum) in which the person curses, shakes his/her body, becomes agitated, exhibits unusual facial expressions, throws objects away, etc.. All of these behaviors are considered a psychological act and a response system or response pattern. The topography of the anger interaction will vary according to the individual's reactive biography and the circumstances surrounding the episode, excluding all other witnesses (Kantor, 1969). All of this would apply to all human emotions, those considered negative (such as depression and anxiety) as well as those considered positive (such as joy and gratitude). Another characteristic of emotions is that they may be reoccurring even if they are of short duration. When applying these criteria to optimism we realize that it does not qualify as an emotion. Unfortunately, certain researchers have an erroneous conceptualization of optimism and view it as a positive emotion even though this may not be theoretically justified (Fredrickson, 2004; Scheier \& Carver, 1985). Contrary to that view, the theoretical perspective supported by this article views the OIS-García as a relatively permanent characteristic of the personality (Mischel, 1980; Ribes, 2009).

Scheier and Carver (1985) and Carver, Scheier, Miller, and Fulford (2009) defined a type of optimism as "dispositional"; as a generalized attitude of positive expectations and results. Thus, the triad of the attitude of optimism, that includes affect, cognition, and behavior, would anticipate more future successes than failures. In addition to this theory of optimism that focuses on goals, hope, and expectations, there is another theoretical perspective proposing that we will expect future positive results as a result of the successes we have had in the past. It would be a prediction or projection based on what we have already experienced. This is an attribution perspective (Peterson \& Seligman, 1984; Peterson, 2000; Seligman, 1991).

Scheier, Carver, and Bridges (1994) developed the LOT-R (life orientation test-revised) while relying on generalized positive expectations perspective. This test was originally developed in English but has been adapted and translated into Spanish. Subsequently, it has been used for research, diagnostic, and intervention purposes by Spanish speaking academicians (Chico, 2002; García \& González, 2010; González \& Landero, 2008; Landero \& González, 2009; Palomar, Victorio, \& Matus, 2011). This instrument seemed to have good psychometric properties with the original sample and with the sample of female Hispanics to which it was administered but it does not validly measure optimism among Hispanic cultures in general (Ferrando, Chico, \& Tous, 2002). "Generalized expectations” as a theoretical model and measurement approach excludes the very important reactive biography of the individual from the analysis (Kantor, 1969). As a result, it cannot provide a holistic view of the "OIS-García". On the other hand, the attribution-related conceptualization of optimism does include the reactive biography of the individual. Unfortunately, there are not scales for measuring optimism stemming from that conceptualization. Finally, to our knowledge there are no scales to measure optimist interaction developed by Latino researchers for use with Latino populations. This realization represents the justification and the impetus for our efforts to develop and validate two cuasi-Likert type scales to measure the OIS-García among Mexicans. The two new scales have 10 items each one with four possible answers for each item: "Yes”, "It seems that yes", "It seems that no", and “No". 


\section{Method}

\section{Participants}

The study comprised a non-probability sample of 350 relatives of a cancer patient who had in turn been part of a larger study related to mental health. The mean age was 39.87 years ( $S D=14.88$ years). The minimum age was 15 years and the maximum was 79 years. One hundred or $28.6 \%$ of the simple were male and 249 or $71.1 \%$ were female. One participant did not identify his/her gender.

\section{Instruments}

The Spanish version of the LOT-R was used to measure dispositional optimism (Otero, Luengo, Romero, Gómez, \& Castro, 1998). The scale comprises 10 items. Six of these, attempt to measure the construct while the other four are simply distracters. Respondents have five possible answers. Three of the response choices are positive statements while 3 of them are negative statements. Scheier et al. (1994) are the creators of the new revised version of the LOT-R. The revised scale's internal consistency is (alpha $=0.78$ ). Perczek, Carver, Price, and Pozo-Kaderman (2000) reported an alpha of 0.79 for the Spanish version they used and an alpha of 0.84 for the original English version. Two versions of the OIS-García developed by the first author of this article were also used. Each version of the scale had 10 question-items. Each question-item was scored on a four point scale ("Yes", "It seems that yes", "It seems that no", and "No") (see Appendix A for full copies of both versions of the scale). The three instruments we used relied on the same answer and scoring system. We did not use the 5 point answer and scoring scale of the original LOT-R. The negative question-items of the LOT-R and all 10 question-items in one of the scales (because all statements related to optimism were negative) were subjected to reverse scorings. This was necessary to ensure proper measurement of dispositional optimism.

\section{Data Collection Procedures}

Students completing their 10th semester in psychology at the Universidad Autónoma de Nuevo León (Monterrey, México) were responsible for all data collection. They administered the socio-demographic questionnaire and the other scales to all participants after they provided informed consent to participate in the study. Study participants responded to all instruments at the public hospital where their relative suffering from cancer had been admitted for treatment. A professional psychologist with experience in working with cancer patients who was also the students' professional practice supervisor trained all of them on how to administer the instruments and how to coordinate the various research activities. All of the students as well as their supervisor received a small financial incentive with funds provided for this purpose by the Federal Government's Department of Public Education.

The items of the three scales were randomly distributed in a multiscale questionnaire or instrument for a total of 126 items. This multiscale instrument was administered to all the cancer patient relatives who also participated in the previous mental health study. The program offered by www.RANDOM.ORG was utilized in preparation for that study.

\section{Study Design}

The study was an "ex post facto", cross-sectional survey design.

\section{Data Analysis}

The SPSS (Statistical Program for Social Sciences) (version 18) and AMOS (Analysis of Moment Structures) (version 20) statistical analyses computer programs were used for data analysis. These programs enabled us to 
calculate all descriptive statistics related to the socio-demographic data and to conduct confirmatory factor analyses for the new scales. They also enabled us to calculate Spearman Rho correlation coefficients.

\section{Results}

The confirmatory factor analyses tested a one-dimensional measurement model of the dispositional optimism construct proposed by the LOT-R, having obtained in general terms a fair goodness of fit (only CFI was not enough good) (Blunch, 2008). This is shown in Table 1.

Table 1

Goodness of Fit of the One-Dimensional Measurement Model of the LOT-R (Six Items) Through Confirmatory Factor Analysis

\begin{tabular}{llll}
\hline Scale & CMIN/DF & CFI & RMSEA \\
\hline LOT-R & 3.258 & 0.69 & 0.08 \\
\hline
\end{tabular}

Notes. CMIN/DF: Minimum value of the discrepancy/degrees of freedom; CFI: Comparative fit index; RMSEA: Root mean square error of approximation.

As observed on Table 2, we were able to improve the goodness of fit by eliminating the item "I usually expect the best during difficult times". This gave us a CR (regression weight estimate/Standard error estimate) $=1.311, p=0.19$.

Table 2

Goodness of Fit of the One-Dimensional Measurement Model of the LOT-R (Five Items) Through Confirmatory Factor Analysis

\begin{tabular}{llll}
\hline Scale & CMIN/DF & CFI & RMSEA \\
\hline LOT-R & 3.048 & 0.824 & 0.077 \\
\hline
\end{tabular}

Notes. CMIN/DF: Minimum value of the discrepancy/degrees of freedom; CFI: Comparative fit index; RMSEA: Root mean square error of approximation.

Nevertheless, the internal consistency coefficient we obtained for this five-item scale with this simple barely reached the precision of 3 in $10(0.315)$.

In Figure 1, we can see a graphic representation of the one-dimensional model of the LOT-R, with the Beta values for the responses to the five items as well as squared multiple correlations for each one of them.

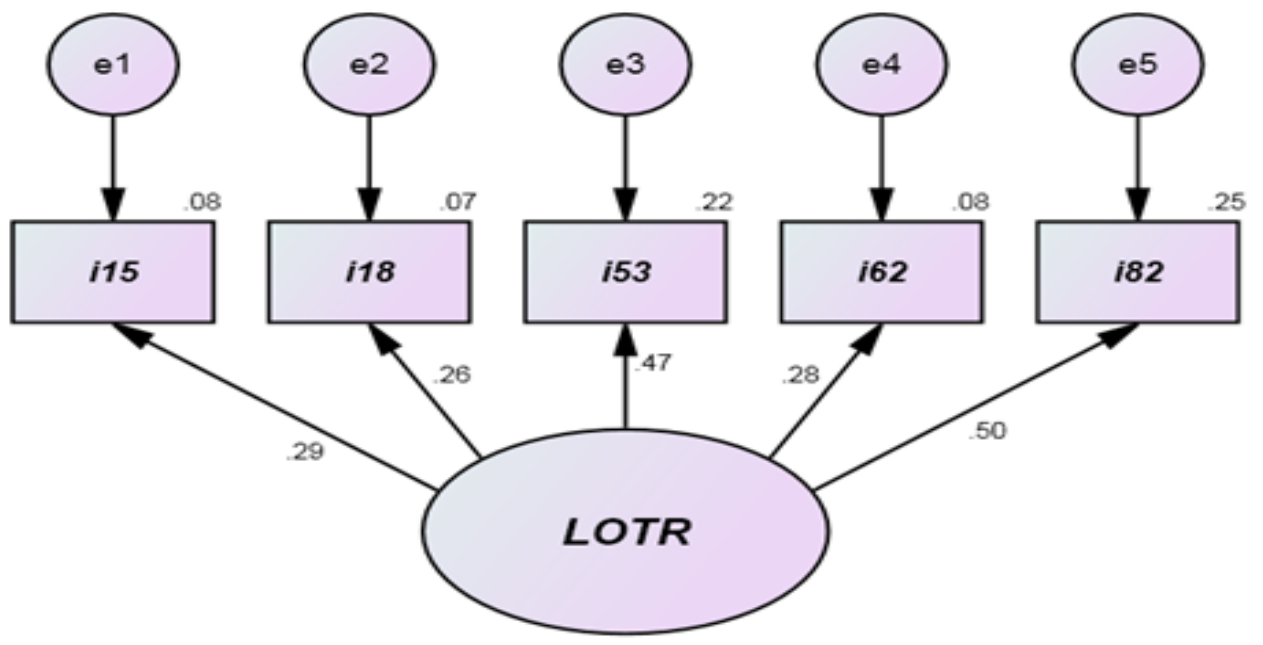

Figure 1. One-dimensional standardized model with five indicators for dispositional optimism estimated by ordinary least. 
A confirmatory factor analysis of the OIS1-García revealed an adequate goodness of fit (Blunch, 2008) as shown in Table 3.

Table 3

Goodness of Fit of the One-Dimensional Measurement Model of the OIS1-Garcia (10 Items) Through Confirmatory Factor Analysis

\begin{tabular}{llll}
\hline Scale & CMIN/DF & CFI & RMSEA \\
\hline OIS1-García & 1.685 & 0.955 & 0.044 \\
\hline
\end{tabular}

Notes. CMIN/DF: Minimum value of the discrepancy/degrees of freedom; CFI: Comparative fit index; RMSEA: Root mean square error of approximation.

Given that the alpha only reached a precision of 5 in $10(\alpha=0.528)$ and that item 91 ("The world is better now than before") was not significant ( $\beta=0.063, p=0.308)$, a decision was made to eliminate this item. This yielded the goodness of fit shown in Table 4 .

Table 4

Goodness of Fit of the One-Dimensional Measurement Model of the OIS1-Garcia (Nine Items) Through Confirmatory Factor Analysis

\begin{tabular}{llll}
\hline Scale & CMIN/DF & CFI & RMSEA \\
\hline OIS1-García & 1.603 & 0.97 & 0.042
\end{tabular}

Notes. CMIN/DF: Minimum value of the discrepancy/degrees of freedom; CFI: Comparative fit index; RMSEA: Root mean square error of approximation.

In spite of the slight improvement in the goodness of fit of the one-dimensional measurement model of nine items, the Chronbach Alpha remained at the previous low level of precision (5 in 10, $\alpha=0.547$ ). We eliminated item 109 ("We can trust others") in an effort to improve the Chronbach alpha given that it had the lowest values among all items ( $\mathrm{CR}=2.028$ ), squared multiple correlation $=0.023$, and a non-significant Beta $(\beta$ $=0.15, p>0.05$ ). The resulting goodness of fit is shown in Table 5 .

Table 5

Goodness of Fit of the One-Dimensional Measurement Model of the OIS1-Garcia (Eight Items) Through Confirmatory Factor Analysis

\begin{tabular}{llll}
\hline Scale & CMIN/DF & CFI & RMSEA \\
\hline OIS1-García & 1.682 & 0.974 & 0.044 \\
\hline
\end{tabular}

Notes. CMIN/DF: Minimum value of the discrepancy/degrees of freedom; CFI: Comparative fit index; RMSEA: Root mean square error of approximation.

The goodness of fit remained very good and the precision of the scale increased to 7 in $10(\alpha=0.701)$, being a good figure for research purposes (Cronbach \& Shavelson, 2004). Figure 2 better illustrates this model.

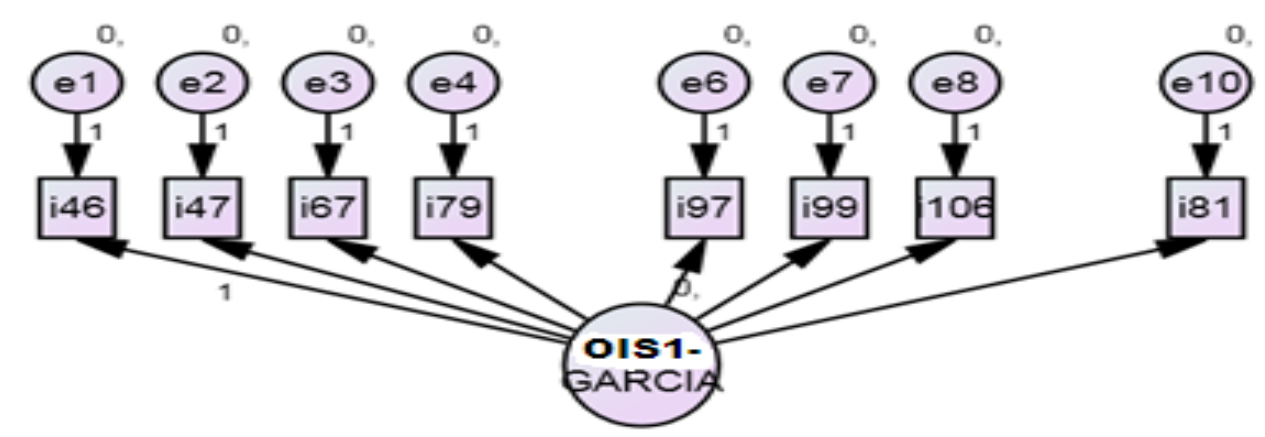

Figure 2. One-dimensional standardized model with eight indicators for OIS1-Garcia estimated by ordinary least squares. 
We were able to establish the one-dimensionality of the OIS2-García and obtain the following indicators of goodness of fit (see Table 6). Such indicators were regular but had very low levels of precision (Almost 4 out of $10, \alpha=0.372$ ).

Table 6

Goodness of Fit of the One-Dimensional Measurement Model of the OIS2-Garcia (10 Items) Through Confirmatory Factor Analysis

\begin{tabular}{llll}
\hline Scale & CMIN/DF & CFI & RMSEA \\
\hline OIS2-García & 2.209 & 0.851 & 0.059
\end{tabular}

Notes. CMIN/DF: Minimum value of the discrepancy/degrees of freedom; CFI: Comparative fit index; RMSEA: Root mean square error of approximation.

We eliminated three non-significant items ("It is very difficult to solve problems", $\beta=0.096, p=0.134$; “The world was better before”, $\beta=-0.040, p=0.528$; and item "The human species will disappear", $\beta=0.113$, $p=0.081$ ). The remaining 7-item model along with its indicators is shown on Table 7. The model reached an alpha of 0.497 (or 5 out of 10 ).

Table 7

Goodness of Fit of the One-Dimensional Measurement Model of the OIS2-Garcia (Seven Items) Through Confirmatory Factor Analysis

\begin{tabular}{llll}
\hline Scale & CMIN/DF & CFI & RMSEA \\
\hline OIS2-García & 2.839 & 0.904 & 0.073
\end{tabular}

Notes. CMIN/DF: Minimum value of the discrepancy/degrees of freedom; CFI: Comparative fit index; RMSEA: Root mean square error of approximation.

In an effort to improve the alpha value, a decision was made to also eliminate item 50 ("Life is bad") given that it had a null squared multiple correlation $=0.041$. This enabled us to reach an alpha value of 0.633 (a precision of 6 in 10).

Table 8 shows the new goodness of fit.

Table 8

Goodness of Fit of the One-Dimensional Measurement Model of the OIS2-Garcia (Six Items) Through Confirmatory Factor Analysis

\begin{tabular}{llll}
\hline Scale & CMIN/DF & CFI & RMSEA \\
\hline OIS2-García & 3.479 & 0.913 & 0.084 \\
\hline
\end{tabular}

Notes. CMIN/DF: Minimum value of the discrepancy/degrees of freedom; CFI: Comparative fit index; RMSEA: Root mean square error of approximation.

Figure 3 graphically illustrates the previously mentioned measurement model for OIS2-García.

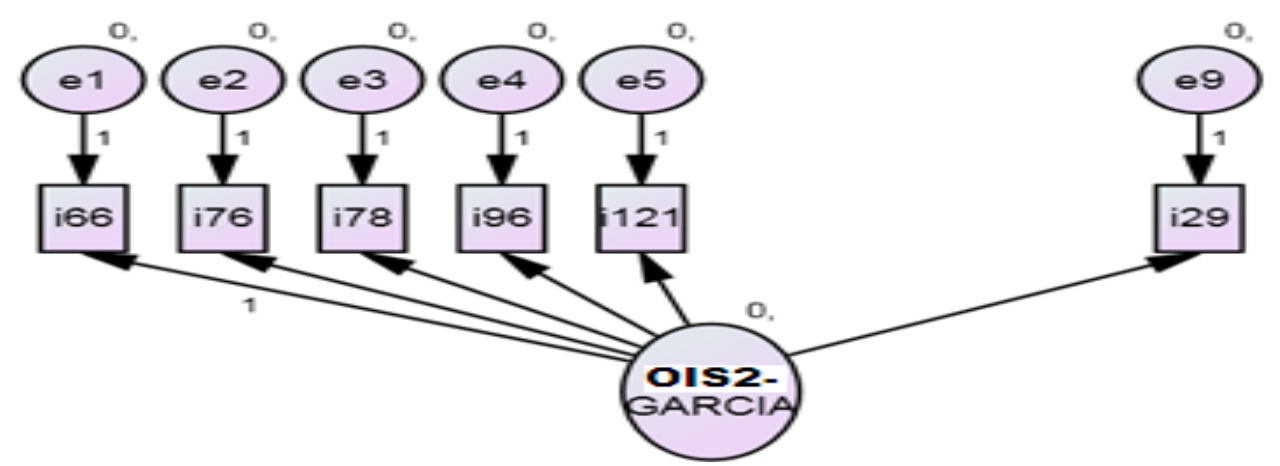

Figure 3. One-dimensional standardized model with six indicators for the OIS2-Garcia estimated by ordinary least squares. 
Table 9

Simple Spearman Correlations Among Scores of the LOT-R, OIS1-Garcia, and OIS2-García Scales

\begin{tabular}{lllll}
\hline Scale & LOT-R & OIS1-García & OIS2-García & $N$ \\
\hline LOT-R & 1.000 & 0.382 & 0.468 & 349 \\
OIS1-García & 0.382 & 1.000 & 0.438 & 349 \\
OIS2-García & 0.468 & 0.438 & 1.000 & 349 \\
\hline
\end{tabular}

\section{Discussion}

The development of instruments to measure specific constructs for particular populations will go a long way in advancing knowledge building in our disciplines. In other words, if we already have a valid and reliable scale for a particular population, it is necessary to create similar scales based on the same latent variable that will satisfy solid psychometric properties for other populations with different socio-economic, political, and cultural contexts. This is precisely the case of Anglo-Saxon and Latino populations. Findings related to this sample are similar to those reported by Landero and González (2009), Palomar, Victorio, and García (2011) and Perczek et al. (2000) about the one-factor structure of the LOT-R, however, the internal consistency Chronbach alpha coefficient was only 0.315. This finding supports the argument of the authors about the need for more culturally appropriate scales that are consistent with idiosyncrasies of both study populations and researchers (García, Carrascoza, \& Díaz, 2013).

At the same time, the use of distracter items in the process of scale design and application seeks to make sure research subjects will respond based on their true personality structures even when they realize what the content of the questions is (Scheier et al., 1994; Snyder, Sympson, Ybasco, Borders, Babyak, \& Higgins, 1996). In this study, we used a different technique to accomplish this goal: random distribution of all scale items using the software found at www.RANDOM.ORG. Future studies will help us determine if this technique contributed to decreasing the precision of the LOT-R $(\alpha=0.315)$. If this were the case, the precision of the technique will depend to some extent on allowing participants to receive the scale, having it in front of them, and knowing what the scale is all about (They would be able to do that in spite of the distracters). This in turn would have an impact on findings.

The moderate simple correlations found among the scores of the OIS1-García, OIS2-García, and the LOT-R ( $\alpha=0.382$ and $\alpha=0.468$, respectively), add convergent validity to the new scales (Campbell \& Russo, 2001; Pedhazur \& Pedhazur Schmelkin, 1991). Similarly, the moderate correlation found among the two versions of García’s OIS-García $(\alpha=0.438)$ strongly suggests that we have found two parallel effective ways of measuring dispositional optimism among Latinos. This should enable practitioners to use the scales for diagnostic, intervention, and research purposes with solid methodological support (for example, when we use an experimental design to evaluate the effectiveness of a clinical, social, or educational intervention). This would eliminate the need to use one scale for pretest and one for post test (Anastasi \& Urbina, 1998; García, 2009).

The measurement model of the OIS-García, the resulting cuasi-Likert type scale, and the related confirmatory factor analyses stemmed from the identification of concepts that focused people's life experiences, and on whether or not they can find solutions to their problems based on those experiences. Their attitude will depend on how they answer the questions of: What is the intrinsic nature of people? (good or bad, trust worthy or unworthy); How is life? (good, bad, ugly, or beautiful); and finally, How is the future? And what does our destiny has in store for us? 
Our theoretical emphasis on reactive biographies (Kantor, 1959; Kantor \& Smith, 1975) is reflected on the way both OIS1-García and OIS2-García were developed. More specifically, our semantic makes reference to what happened in the past and from there we depart to what we expect in the future. Particularly, the discourse that recreates reality is found in items "There are solutions to problems", "Human beings are good”, "Men are born good", and "Life is beautiful". We cannot trust that there are solutions to problems, that people are intrinsically good, and that life is beautiful if we have never symbolically or really experienced these positive aspects of life.

The other four items of the OIS1-García, reflect the same type of optimism: "You has done well in life", "A good future awaits us", "Hope compensates for the worst", and "Life is good". Similarly, we could argue that we believe that "Hope compensates for the worst", that "life is good", and that "a good future awaits us" only because we have had favorable experiences. The same reasoning related to the interbehavioral construct and the reactive biographies is applied to the OIS2-Garcíain spite of the language of the reverse scoring items: "Things have not gone well for you in life”, "Men are born evil”, "Men are evil”, "Hope is just an illusion”, and "Life is ugly".

On the other hand, the conceptualization of the LOT-R does not favor the reactive biographies but instead favors the concept of favorable expectations. As a result, the items in the scale revolve around that construct. The LOT-R devalues the influence of prior life experiences over how we perceive our current or future life: "You are always optimistic about the future", "In general, you anticipate more good than bad things", "If something bad must happen to you, you are sure it will happen to you", "You rarely expect good things to happen to you", and "You rarely expect things to happen your way".

Finally, a limitation of this study is that it relied on a sample of convenience, which prevents the generalizability of findings and their applicability to other samples or populations. For this reason, we encourage more rigorous research that will further test the psychometric properties of the proposed instruments.

\section{References}

Academy Royal of the Spanish Language. (2001). Dictionary of the Spanish language (22nd ed.). Retrieved January 28, 2012, from http://buscon.rae.es./draeI

Anastasi, A., \& Urbina, S. (1998). Tests psicológicos (Psychological testing). México: Prentice-Hall.

Blunch, N. H. (2008). Introduction to structural equation modeling using SPSS and AMOS. Thousand Oaks: Sage Publications.

Campbell, D. T., \& Russo, M. J. (2001). Social measurement. Thousand Oaks: Sage Publications.

Carver, Ch. S., Scheier, M. F., Miller, Ch. J., \& Fulford, D. (2009). Optimism. In C. R. Snyder, J. Sh., \& Lopez (Eds.), Handbook of positive psychology (pp. 303-312). New York: Oxford University Press.

Chico Librán, E. (2002). Optimismo disposicional como predictor de estrategias de afrontamiento (Dispositional optimism as predictor of coping strategies). Psicothema, 14(3), 544-550.

Cronbach, L. J., \& Shavelson, R. J. (2004). My current thoughts on coefficient alpha and successor procedures. Educational and Psychological Measurement, 64(3), 391-418. DOI: 10.1177/0013164404266386

Ferrando, P., Chico, E., \& Tous, J. (2002). Propiedades psicométricas del test de optimismo life orientation test (Psychometric properties of optimism test life orientation test). Psicothema, 14, 673-80.

Fredrickson, B. L. (2004). The broaden-and-build theory of positive emotions. University of Michigan.

García, C. H. (2009). Como investigar en psicología (How to research in psychology). México: Trillas.

García, C. H., Carrascoza, C. A., \& Díaz, H. L. (2013). Psychological theory and research in Mexico: Critical reflections. International Journal of Psychology Research, 8, 2.

García, R., \& González Ramírez, M. T. (2010). Relationship between stress and optimism in ischemic cardiomyopathy patients. International Journal of Hispanic Psychology, 3(1), 61-70. 
González, M. T., \& Landero, R. (2008). Cambios en optimismo e impacto de la fibromialgia después de un curso virtual (Changes in optimism and impact of fibromyalgia after a virtual course). Interpsiquis 1, 2008. Retrieved December 9, 2012, from http://www.psiquiatria.com/articulos/psicosomatica/34029/

Kantor, J. R. (1959, revised edition). Interbehavioral psychology. Bloomington, I.N.: Principia Press.

Kantor, J. R. (1969, third reprint). Principles of psychology. Bloomington, I.N.: Principia Press.

Kantor, J. R., \& Smith, N. W. (1975). The science of psychology: An interbehavioral survey. Chicago, I.L.: Principia Press.

Kantor, J. R. (1982). Cultural psychology. Chicago, I.L.: Principia Press.

Landero Hernández, R., \& González Ramírez, M. T. (2009). Propiedades psicométricas de la versión española del test de optimismo revisado (LOT-R) en una muestra de personas con fibromyalgia (Psychometric properties of the Spanish version of revised optimism test (LOT-R) in a sample of persons suffering fibromyalgia). Ansiedad y Estrés, 15(1), 111-117.

Matsumoto, D. (Editor). (2009). The Cambridge dictionary of psychology. Cambridge: Cambridge University Press.

Mischel, W. (1980). Personalidad y evaluación (Personality and assessment). México: Trillas.

Otero, J. M., Luengo, A., Romero, E., Gómez, J. A., \& Castro, C. (1998). Psicología de la personalidad: Manual de prácticas (Psychology of personality: A handbook). Barcelona: Ariel Practicum.

Palomar Lever, J., Victorio Estrada, A., \& Matus García, G. L. (2011). Sentido del humor y optimismo: Un estudio de validación (Sense of humor and optimism: A validation study). Revista Interamericana de Psicología, 45(2), 123-132.

Pedhazur, E. J., \& Pedhazur Schmelkin, L. (1991). Measurement, design, and analysis: An integrated approach. Hillsdale: Lawrence Erlbaum Associates Inc..

Perczek, R., Carver, C. S., Price, A. A., \& Pozo-Kaderman, C. (2000). Coping, mood and aspects of personality in Spanish translation and evidence of convergence with English versions. Journal of Personality Assessment, 74, 63-87.

Peterson, C., \& Seligman, M. E. P. (1984). Causal explanations as a risk factor for depression: Theory and evidence. Psychological Review, 91, 347-374.

Peterson, C. (2000). The future of optimism. American Psychologist, 55, 44-55.

Piña López, J. A., Ybarra Sagarduy, J. L., Alcalá Sánchez, I. G., \& Samaniego Garay, R. A. (2010). Psicología y salud [I]: La importancia de llamarse Modelo y apellidarse Teórico-conceptual (Psychology and health [I]: The importance of be called model and having as last name theorethical-conceptual). Revista Mexicana de Investigación en Psicología, 2(1), 23-31.

Ribes, E., \& Sánchez, S. (1990). El problema de las diferencias individuales: un análisis conceptual de la personalidad (The problem of individual differences: A conceptual analysis of personality). In E. Ribes (Ed.), Problemas conceptuales en el análisis del comportamiento (Conceptual problems in behavior analysis) (pp. 79-99). México: Editorial Trillas.

Ribes, E., \& Sánchez, S. (1992). Individual behavior consistencies as interactive styles: How related to personality? The Psychological Record, 42, 369-387.

Ribes, E. (2005). ¿Qué es lo que se debe medir en psicología? La cuestión de lasdiferencias individuals (What should be measured in psychology? The issue of the individual differences). Acta Comportamentalia, 13(1), 37-52.

Ribes, E. (2009). La personalidad como organización de los estilos interactivos (The personality like organization of the interactive styles). Revista Mexicana de Psicología, 26, 145-161.

Scheier, M., \& Carver, C. (1985). Optimism, pessimism and health: Assessment and implication of generalized outcomes expectancies. Health Psychology, 4, 219-247.

Scheier, M. F., Carver, C. S., \& Bridges, M. W. (1994). Distinguishing optimism from neuroticism (and trait anxiety, self mastery and self esteem): A reevaluation of the Life Orientation Test. Journal of Personal Social Psychology, 67(1), 63-78.

Seligman, M. E. P. (1991). Learned optimism. New York: Knopf.

Snyder, C. R., Sympson, S. C., Ybasco, F. C., Borders, T. F., Babyak, M. A., \& Higgins, R. L. (1996). Development and validation of the state hope scale. Journal of Personality and Social Psychology, 70, 321-335.

\section{Appendix A}

Escalas de Estilo Interactivo Optimista (Optimism Interactive Scales)

EI01-García (0IS1-García)

46-La esperanza compensa lo peor (46-Hope compensates for the worst)

47-Hay soluciones para los problemas (47-There are solutions to problems)

$67-$ El ser humano es bueno (67-Human being is good) 
79-El hombre nace bueno (Men are born good)

81-La vida es Hermosa (Life is beautiful)

91-Ahora el mundo es mejor que antes (The world is better now than before)

97-Nos espera un buen future (A good future awaits us)

99-La vida es Buena (Life is good)

106-Le ha ido bien en la vida (Things have gone well for you in life)

109-Se puede confiar en los demás (We can trust others)

EI02-Garcia (OIS2-Garcia)

4-Es muy difícil solucionar los problemas (It is very difficult to solve problems)

29-Se debe desconfiar de los demás (It is necessary not trust in others)

31-Antes era mejor el mundo (The world was better before)

39-La especie humana desaparecerá (The human species will disappear)

50 -La vida es mala (Life is bad)

66-Le ha ido mal en la vida (Things have not gone well for you in life)

76-El hombre nace malo (Men are born evil)

78-El hombre es malo (Men are evil)

96-La esperanza es pura illusion (Hope is just an illusion)

121-La vida es fea (Life is ugly) 